6-ARTIGO ORIGINAL

\title{
Estudo comparativo do uso de cola de fibrina e cianoacrilato em ferimento de fígado de rato ${ }^{1}$
}

\author{
Carlos Edmundo R. Fontes ${ }^{2}$, Murched Omar Taha ${ }^{3}$, Djalma José Fagundes ${ }^{4}$, Marcos Victor Ferreira ${ }^{5}$, \\ Orlando R. Prado Filho², Marino Jose Mardegan ${ }^{5}$
}

\begin{abstract}
Fontes CER, Taha MO, Fagundes DJ, Ferreira MV, Prado Filho OR, Mardegan JM. Estudo comparativo do reparo de ferimento de fígado com cola de fibrina e cianoacrilato. Acta Cir Bras [serial online] 2004 Jan-Fev;19(1). Disponível em URL: http://www.scielo.br/acb
\end{abstract}

RESUMO - Objetivo: estudar comparativamente o uso de cianoacrilato e cola de fibrina no reparo do ferimento hepático, para evidenciar suas respectivas capacidades de integração aos tecidos à curto prazo. Métodos: 30 ratos Wistar-EPM1 foram separados em 2 grupos e submetidos à anestesia com tiopental na concentração de 40mg/kg EV. Realizada laparotomia com exposição do fígado. Usando um "punch" dermatológico de $3 \mathrm{~mm}$ foi produzido um ferimento padronizado em lobo direito hepático. Os animais do grupo A foram tratados com a colocação de cola de fibrina nos ferimentos, os animais do grupo B tiveram os ferimentos tratados com adesivo de cianoacrilato. No $7^{\circ}$ de PO, sob anestesia, os animais sofreram a ressecção do lobo hepático direito e foram coletadas amostras para os procedimentos de estudo histológicos (HE e Picro-Sirius). Foram avaliados, por microscopia óptica, os processos inflamatórios (critérios qualitativos da presença de neutrófilos, células gigantes, granuloma tipo corpo estranho, neovascularização) e, por microscopia de polarização, a quantificação de colágeno (Tipo I-jovem e Tipo III-maduro). Resultados: Os dois adesivos levaram ao efeito hemostático em tempos semelhantes. Os ferimentos tratados com cola de fibrina mostraram maior quantidade de colágeno jovem e maduro e uma maior quantidade de neovascularização, enquanto os ferimentos tratados com cianoacrilato mostraram maior reação de granuloma tipo corpo estranho. Conclusão: $O$ ferimento tratado com a cola de fibrina apresentou maior neovascularização e maior porcentagem de colágeno tipo I e tipo III demonstrando tendência a uma melhor reparação tecidual, sem formação de granuloma tipo corpo estranho.

DESCRITORES - Hemostasia. Adesivo tecidual de fibrina. Fígado.

\section{Introdução}

A cirurgia é certamente o ramo mais antigo da terapêutica. Seu início confunde-se na pré-história com o aparecimento do homem primitivo, quando em sua luta pela existência estava continuamente em conflitos com animais que caçava ou que o perseguiam $^{1,2,3}$. As feridas necessitavam de tratamento imediato por métodos primitivos como a pressão, a aplicação de musgo e teias de aranha ${ }^{2,4}$.
Foi uma exibicionista de circo de nome Gamba Curta que no início do século XIX, a primeira pessoa a utilizar uma substância capaz de colar tecido biológico. Ela fazia demonstrações de retirada de fragmentos da própria pele e depois as colava com uma mistura que produzia a fixação e cicatrização . O conhecimento destas exibições permitiu que Barônio (1804) tentasse transplantes de fragmento de pele da cauda de ovelhas, usando para a fixação este mesmo material ${ }^{2,4}$.
Sano (1943) descreve um método para fixar retalhos de pele sem sutura ou curativos compressivos, empregando mais princípios de cultura de tecidos do que uma substância com propriedades adesivas. Seu método foi empregado por vários autores, tais como Harris, Babcock, Clarke. Esse método foi usado principalmente em queimados durante a Segunda Guerra Mundial ${ }^{2,4}$.

Na década de 50 Bloch utilizou resina de epoxilina em fraturas experimentais.

1. Trabalho na Disciplina de Técnica Operatória da Universidade Estadual de Maringá (UEM) e Disciplina de Técnica Operatória e Cirurgia Experimental da Universidade Federal de São Paulo (UNIFESP-EPM).

2. Professor Adjunto da Clínica Cirúrgica da UEM.

3. Professor Orientador do Programa de Pós-Graduação em Técnica Operatória e Cirurgia Experimental da UNIFESP-EPM.

4. Professor Adjunto do Depto. de Cirurgia da UNIFESP-EPM e Coordenador do Programa de Pós-Graduação em Técnica Operatória e Cirurgia Experimental da UNIFESP-EPM.

5. Professor Assistente da Clínica Cirúrgica da UEM. 
Mandarino e Salvatori utilizaram polímeros de poliuretano como adesivo também na consolidação de fraturas ${ }^{2,4}$.

Em 1951 um químico da Eastman Kodak, determinando as propriedades de monômeros derivados de acrilatos, verificou, ao medir o índice de refração de um destes compostos, que o mesmo havia colado os prismas do refratômetro. Surgiu, dessa forma, o alquil-2-cianoacrilato que recebeu o nome comercial EASTMAN-910, da Eastman Kodak Company. No final dos anos 50 e em toda década de 60, o alquil2-cianoacrilato e derivados (com cadeias laterais mais longas ou mais curtas, retas ou quebradas) foram utilizados em animais e na espécie humana como adesivos sintéticos, praticamente em todos os tecidos orgânicos 1,3,4,5.

Em 1911, paralelamente aos estudos utilizando substâncias adesivas, Cushing usou fragmentos de coágulos solidificados para hemostasia; Grey continuou experimentos usando fibrina extraída de sangue ovino para controlar sangramento de lacerações cutâneas e cerebrais em cães e gatos. Harvey, por sua vez, converteu fibrina bovina num material hemostático, semelhante a papel, usado no reparo de feridas e em anastomoses intestinais ${ }^{6,7,8}$.

No entanto, a partir de 1970 é que a cola de fibrina ganhou nova importância com o desenvolvimento de técnicas de microcirurgia $^{7,8}$.

O presente trabalho procurou estudar comparativamente o uso de cianoacrilato e cola de fibrina no reparo do ferimento hepático, para evidenciar a capacidade integração aos tecidos à curto prazo.

\section{Métodos}

Foram usados 30 ratos Wistar EPM1, machos, peso com variação de 200 a 250 gramas provenientes de Biotério da Universidade Estadual de Maringá, que foram separados em 2 Grupos: Grupo A - ferimento tratado com cola de fibrina e Grupo B - ferimento tratado com cianoacrilato. Os animais foram confinados em gaiolas apropriadas para ratos em ambiente com controle de temperatura e umidade. Fotoperíodo de $12 \mathrm{~h}$ controlado por "timer". Ração peletizada própria para a espécie e água a vontade.
A anestesia endovenosa foi aplicada pela veia caudal usando tiopental sódico na dose de 40mg/Kg de peso.

Tricotomia da região ventral com aparelho elétrico, anti-sepsia com iodo polividona, colocação dos panos operatórios esterilizados delimitando o campo cirúrgico. Laparotomia mediana de $3 \mathrm{~cm}$ de extensão com bisturi a partir do processo xifóide, interessando pele, tela subcutânea, músculo reto abdominal e peritônio parietal. Identificação do lobo direito hepático e realização de ferimento com "punch" dermatológico de $3 \mathrm{~mm}$ de diâmetro e $5 \mathrm{~mm}$ de profundidade. Após manobra de compressão e limpeza local do ferimento, nos animais do Grupo A foi colocado $1 \mathrm{ml} \mathrm{de}$ cola de fibrina por gotejamento sobre o ferimento. Nos animais do Grupo B foi colocado $1 \mathrm{ml}$ de cianoacrilato por gotejamento sobre o ferimento. Após a colocação dos adesivos na área cruenta do fígado foram observados o tempo e eficácia do efeito hemostático. Ficou estabelecido um tempo de observação de três minutos para a concretização do efeito hemostático e depois a cavidade abdominal foi suturada.

A cavidade foi fechada com fio de poliamida 4-0, separadamente, por sutura contínua da camada músculo-aponevrótica e sutura continua a pele.

\section{Resultados}

TABELA 1 - Ratos submetidos a ferimento em fígado e colocação de cianoacrilato ou cola de fibrina na ferida, segundo a porcentagem de colágeno tipo I nos cortes histológicos observados á microscopia de polarização (Picrus-Sirius - aumento de 80X).

\begin{tabular}{cc}
\hline Grupo A & Grupo B \\
\hline Fibrina & Cianoacrilato \\
\hline 6,20 & 18,10 \\
22,50 & 12,40 \\
24,00 & 6,00 \\
35,70 & 2,00 \\
2,10 & 8,30 \\
8,70 & 7,20 \\
0,20 & 7,70 \\
9,50 & 3,90 \\
10,40 & 3,40 \\
29,40 & 7,70 \\
11,50 & 2,50 \\
14,60 & 3,20 \\
13,40 & 3,00 \\
15,00 & 5,40 \\
16,70 & 4,70 \\
\hline 14,66 & 6,37 \\
\hline Média & Análise de variância por postos de Kruskal-Wallis \\
\hline Heste de comparações múltiplas & \\
Cola de fibrina $>$ cianoacrilato & \\
\hline
\end{tabular}

No $7^{\circ}$ dia de pós-operatório os animais foram submetidos a laparotomia, usando a mesma técnica anestésica e mesma técnica operatória descrita anteriormente, e os achados macroscópicos foram anotados em formulário próprio. Os segmentos de fígado após serem retirados e encaminhados para o laboratório de histologia da Universidade Estadual de Maringá para preparação histológica pela técnica convencional de inclusão em parafina e seccionados com micrótomo perpendicularmente à área a ser estudada produzindo cortes com solução de hematoxilina e eosina.

A interpretação dos achados histológicos teve como base critérios qualitativos da presença de neutrófilos, células gigantes, granuloma tipo corpo estranho, neovascularização. As leituras histológicas foram feitas usando microscopia óptica e com aumentos de 80x e 100x.

O estudo da presença de colágeno, quanto ao aparecimento da forma jovem e madura, foi feito por coloração dos cortes histológicos pela técnica de Picrus-Sirius, a leitura foi feita por microscopia de polarização e as imagens foram analisadas por do colágeno tipo I (jovem) e tipo III (maduro). com espessura de 5 micrômeros e corados analisador de imagens para quantificação 
TABELA 2 - Ratos submetidos a ferimento em fígado e colocação de cianoacrilato ou cola de fibrina na ferida, segundo a porcentagem de colágeno tipo III nos cortes histológicos observados á microscopia de polarização (Picrus-Sirius - aumento de 80X)

\begin{tabular}{cc}
\hline Grupo A & Grupo B \\
\hline Fibrina & Cianoacrilato \\
\hline 6,30 & 18,00 \\
7,40 & 2,00 \\
13,40 & 0,60 \\
45,00 & 0,50 \\
7,60 & 1,20 \\
15,50 & 0,40 \\
0,10 & 1,20 \\
17,20 & 0,20 \\
19,30 & 0,30 \\
29,80 & 0,70 \\
12,00 & 0,40 \\
18,00 & 0,40 \\
21,80 & 0,50 \\
26,40 & 0,60 \\
27,10 & 0,20 \\
\hline 17,79 & 1,81 \\
\hline Teste de comparações múltiplas & \\
Cianoacrilato<fibrina & \\
Análise de variância por postos de Kruskal-Wallis & \\
H calculado $=24,74 *$ & H crico $=5,99$ \\
\hline ( $=0,01)$ & \\
\hline & \\
\hline
\end{tabular}

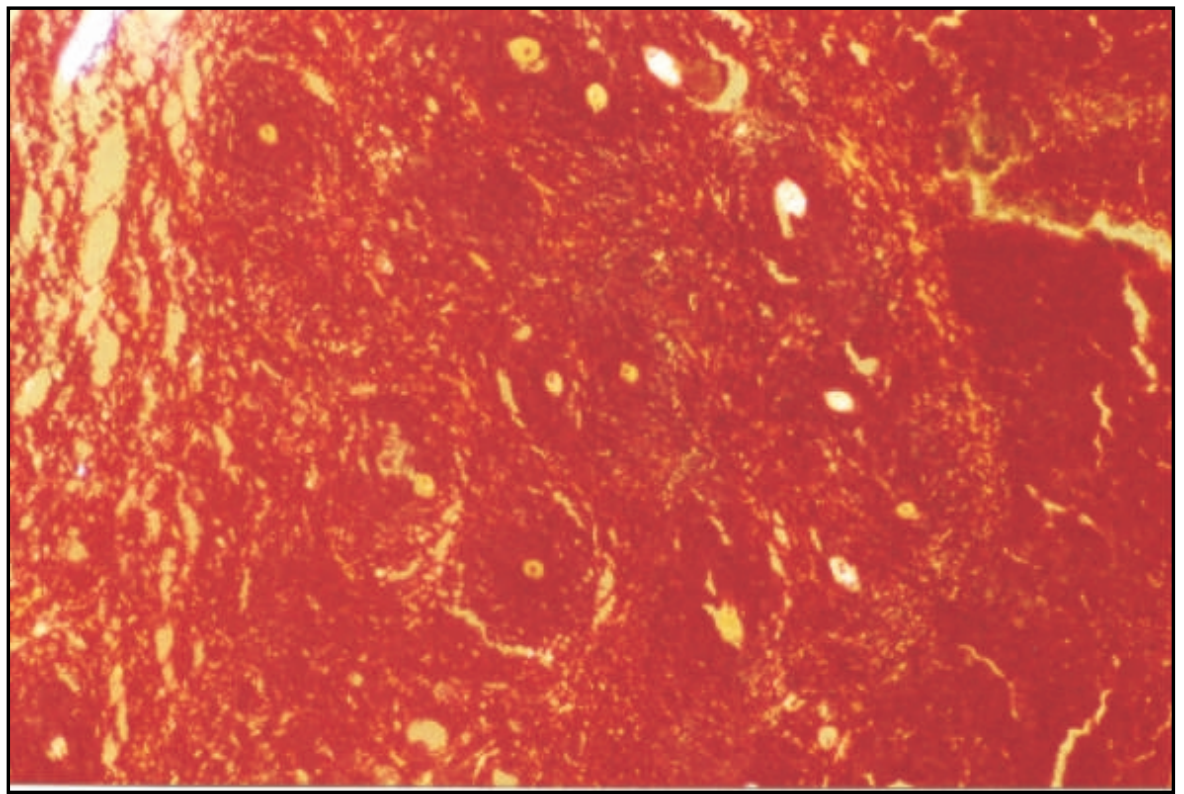

FIGURA 1 - Fotomicrografia de corte histológico em lesão hepática reparada com cola de fibrina mostrando a área de regeneração do tecido hepático sem formação de granuloma tipo corpo estranho (HE - aumento 100X).

\section{Discussão}

O animal escolhido para este estudo foi o rato devido às suas características biológicas e seu metabolismo aumentado em relação ao homem, podendo desta maneira admitir uma análise tardia em relação ao processo de cicatrização em tempo menor de observação. Outro aspecto importante na escolha foi a facilidade de se obter uma
$\mathrm{Kg}$, por apresentar um bom poder de sedação e de relaxamento. A via venosa foi necessária uma vez que o procedimento a ser realizado poderia sofrer interferência do fármaco se administrado na cavidade abdominal. Não ocorreram acidentes anestésicos e o período de sedação foi suficiente para os procedimentos operatórios previstos.

A cola de fibrina é um adesivo de fibrina composto por fibrinogênio humano altamente purificado, concentrado e pasteurizado, fator XIII e trombina humana que são reconstituídos em soluções com agente antifibrinolítico e aprotinina, derivado de tecido pulmonar de bovinos e solução de cloreto de cálcio, reproduzindo os últimos passos da coagulação representando um mecanismo fisiológico na hemostásia ${ }^{1,3,9,10,11}$.

O cianoacrilato age por polimerização ao contato com as proteínas orgânicas que funcionam como catalisadores produzindo uma reação exotérmica e deixando uma crosta na superfície da ferida. Deve-se salientar seu poder bactericida e bacteriostático, mínima toxidade tecidual e sua cor azul facilita a visibilização do produto no campo operatório ${ }^{1,3,4,5,13}$.

$\mathrm{O}$ ferimento padronizado foi estabelecido à partir do estudo de um grupo piloto. $\mathrm{A}$ área e profundidade escolhidas do ferimento foram aquelas em que, se não usasse nenhum procedimento hemostático, levaria a um sangramento que persistiria por cerca de dez minutos ou mais.

A hemostasia do ferimento provocado foi conseguida nos dois grupos antes do fechamento da cavidade, o que ocorreu em cerca de três minutos após a aplicação e que corresponde à cerca de $30 \%$ do tempo que levaria sem uso de produtos hemostáticos. A análise dos resultados mostra que ambos os adesivos produziram a hemostasia em tempos semelhantes (dentro dos prazos estabelecidos) não havendo sob este critério nenhuma vantagem de um sobre o outro.

A parte técnica de aplicação de ambos os adesivos foram semelhantes não havendo, no procedimento estudado, dificuldades em aplicação dos adesivos. Não houve adesividade às luvas cirúrgicas ou ao instrumental; não houve dificuldade de formar a placa de adesivo sobre o ferimento; não houve escape ou deslocamento 


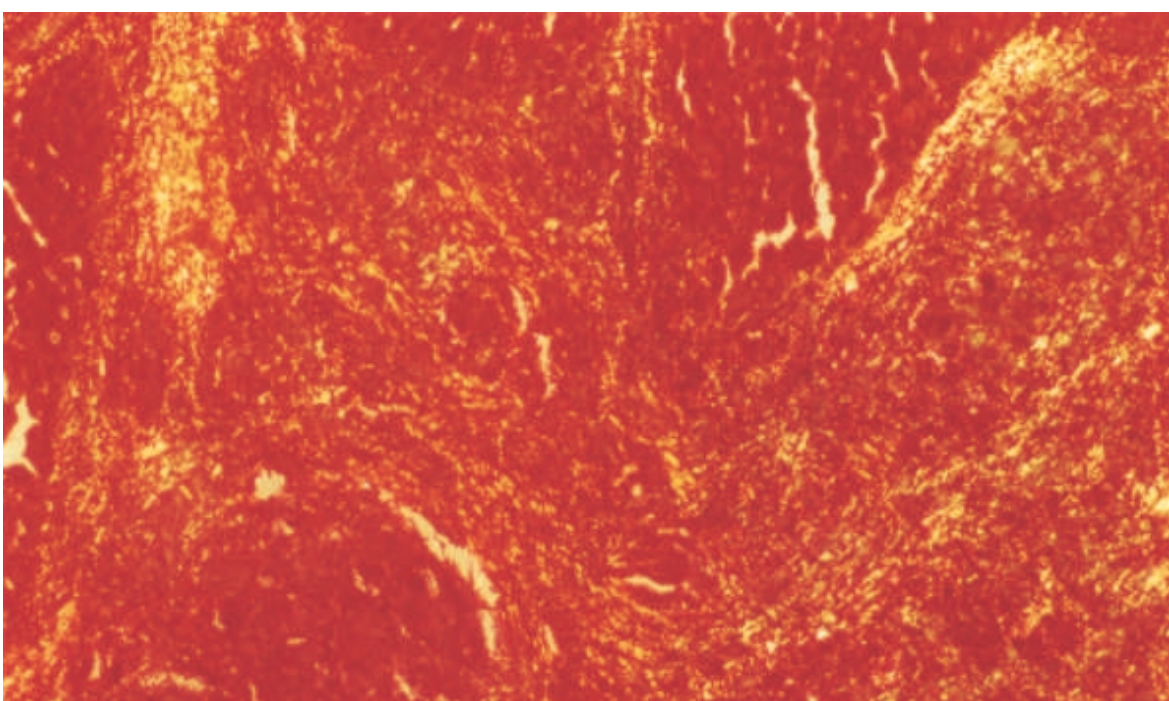

FIGURA 2 - Fotomicrografia de corte histológico em lesão hepática reparada com cola de fibrina mostrando a alteração estrutural na área de regeneração do tecido hepático com formação de granuloma tipo corpo estranho (HE - aumento 100X).

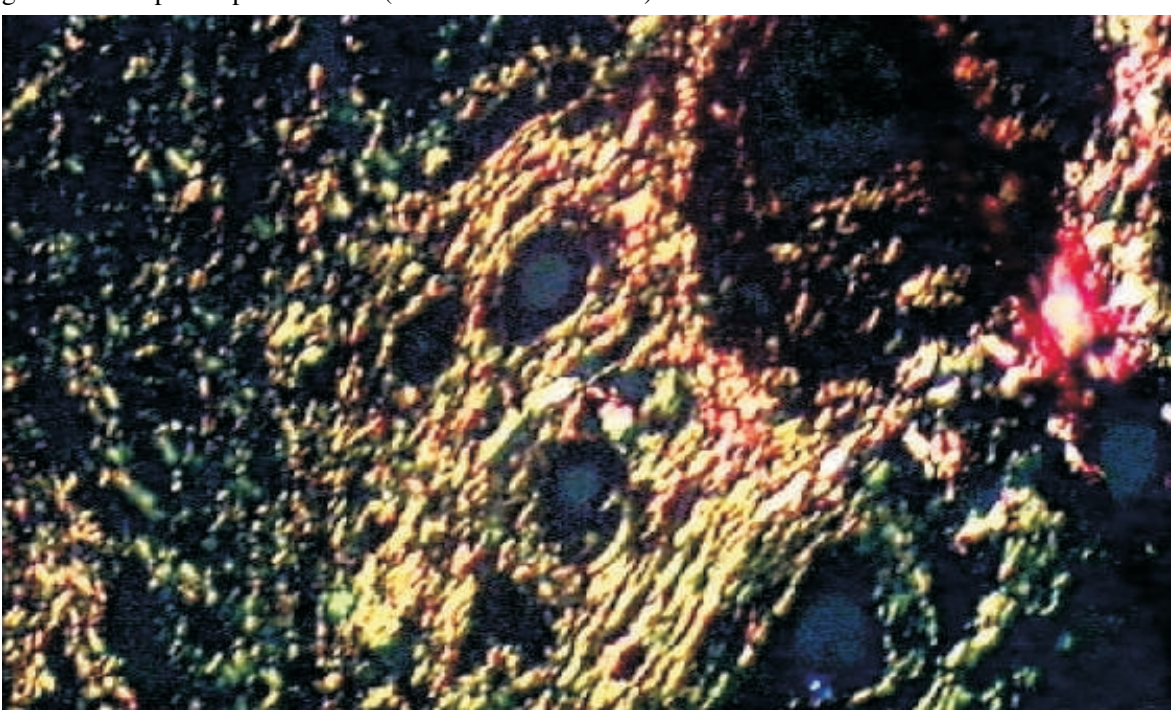

FIGURA 3 - Fotomicrografia de corte histológico de ferimento de fígado tratado com cola de fibrina e o predomínio de colágeno jovem -Tipo I (Picrus-Sirius - aumento de 80X).

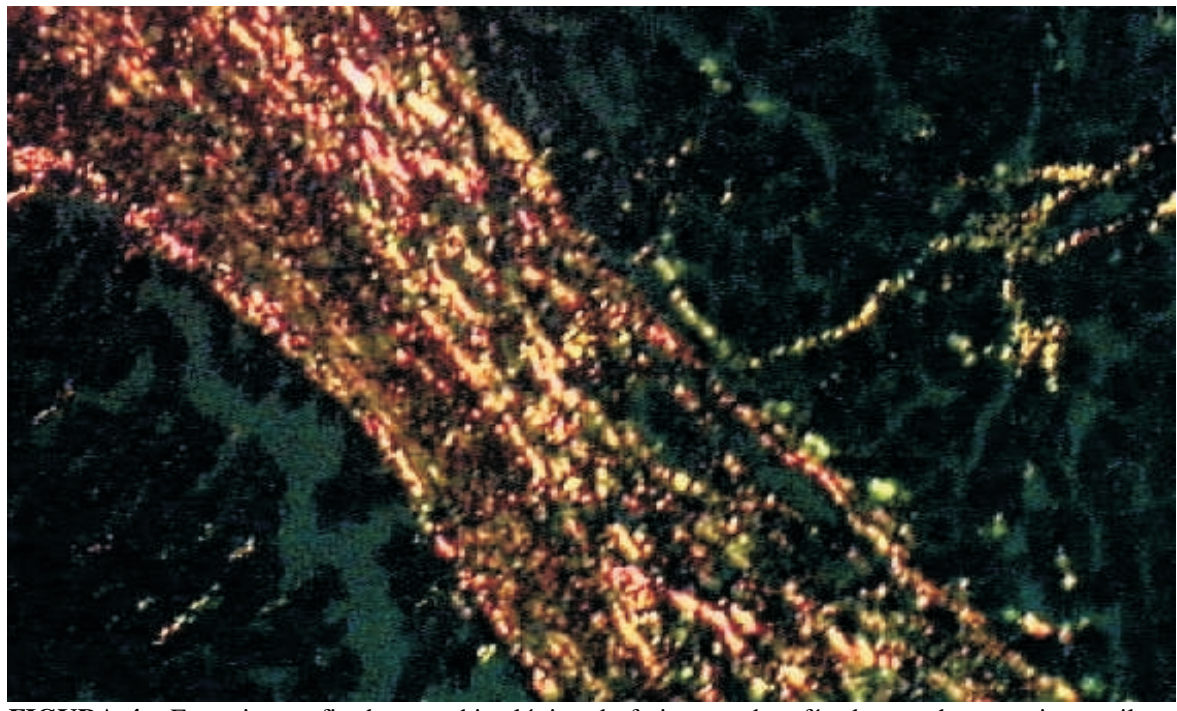

FIGURA 4 - Fotomicrografia de corte histológico de ferimento de fígado tratado com cianoacrilato, menor trama de colágeno com predomínio de colágeno maduro-Tipo III (Picrus-Sirius - aumento de $80 \mathrm{X})$. da placa do adesivo do ferimento; não houve necessidade de novas aplicações ou reforço de adesivo sobre o ferimento Um aspecto que deve ser salientado quanto ao uso de ambos os adesivos diz respeito à necessidade prévia de compressão e "limpeza" do ferimento antes da aplicação. A hemorragia volumosa acelera a polimerização do cianoacrilato impossibilitando seu uso, e não permite a reação para obtenção do coágulo estável da cola de fibrina. O manuseio do cianoacrilato deve ser muito cuidadoso, por apresentar poder adesivo maior que a fibrina, o extravasamento do produto fora da ferida poder levar a aderências indesejáveis ${ }^{5,14}$.

No $7^{\circ}$ dia de pós-operatório os fígados de todos os ratos de ambos os grupos mostram aderências da área lesada à parede abdominal e ao omento, não sendo observado sinais de peritonite ou fístula em nenhum animal. Não houve diferença estatística quanto a aderências pois em todos os animais, de ambos os grupos, elas estiveram presentes e com características semelhantes.

A reação inflamatória desencadeada em ambos os grupos foi muito parecida, sob o aspecto histológico observado à microscopia óptica, quanto à presença de neutrófilos e células gigantes.

A reação de granuloma tipo corpo estranho foi mais intensa no grupo tratado com cianoacrilato (Figuras 1 e 2), embora não tenha sido possível estabelecer uma significância estatística pela natureza da análise que foi somente sob o ponto de vista qualitativo. A maior reação inflamatória tipo corpo estranho do adesivo de cianoacrilato deve-se ao fato de ser um material sintético e os achados são concordantes com outros trabalhos que usam dos diversos tipos de cianoacrilatos $1,3,5$, 12,14

O estímulo a neoformação vascular foi maior no grupo tratado com cola de fibrina (Figura 1) como é característico deste tipo de adesivo e destacado por outros trabalhos na literatura 6,7,8,9,12. A neovascularização é tida como uma grande vantagem do adesivo de fibrina pois estaria facilitando a reparação tecidual e a cicatrização.

A cicatrização é uma série de eventos biológicos que começa com a hemostasia, mas que, a seguir, envolve uma resposta 
inflamatória, a formação de tecido conjuntivo e a remodelagem da ferida.

A cicatrização constitui fenômeno químico, físico e biológico que ocorre após lesão de qualquer natureza, possuidora de várias fases que se superpõem e se relacionam reciprocamente, constituindo um processo harmônico, único e contínuo 5

Das fases da cicatrização destaca-se a de fibroplasia notada 48 horas após a execução da lesão, caracterizada pela invasão de fibroblastos que se multiplicam, proliferam e passam a secretar as proteínas características do tecido em reparação².

O fibroblasto produz a substância fundamental (amorfa-mucopolissacarídeos) envolvida com a produção e orientação das fibras colágenas bem como o tamanho dessas fibras e a síntese propriamente de colágeno ${ }^{7}$.

As primeiras fibras colágenas surgem em quatro a cinco dias. No início da fase proliferativa , a síntese e a lise de colágeno se dão simultaneamente. Qualquer intensificação da lise ou atraso ou diminuição da síntese podem causar a deiscência de uma ferida ou anastomose ${ }^{11,12}$.

O colágeno é o responsável pela força e integridade de todos os tecidos, sendo que a força e a integridade do tecido de reparação reside no tipo e na quantidade de fibras colágenas ${ }^{8,15}$.

Portanto, é de grande relevância na reparação tecidual a concentração de fibras de colágeno que dão orientação as células epiteliais que migram sobre a superfície lesada. Estas fibras são classificadas em tipo I e III conforme seu grau de maturação, a mensuração destas fibras é de extrema importância quando queremos comparar a reparação tecidual ${ }^{15,16,17,18}$.

O uso da coloração de picrosirius foi de grande importância para a mensuração do colágeno jovem e maduro ao colorir a proteína das fibras em verde a forma jovem e vermelho a madura ( tipo I, e III ).

A observação na microscopia de polarização por birrefrigência permitiu a identificação e quantificação dos dois tipos de colágenos. A cola de fibrina favoreceu o aparecimento de fibras colágenas tanto do tipo I quanto do tipo III (Figuras 3 e 4 ) em porcentagem estatisticamente significante em relação ao cianoacrilato favorecendo desta forma a reparação tecidual (Tabelas 1 e 2).

Considerando os dados obtidos pode-se afirmar que do ponto de vista técnico a aplicação de ambos os adesivos foram equivalentes. No entanto do ponto de vista histológico o adesivo de fibrina mostrou-se mais adequado uma vez que causou menor reação tipo corpo estranho e está associado a uma maior quantidade de fibras colágenas, o que configura um processo de reparação ou cicatrização mais favorável.

\section{Conclusões}

O ferimento tratado com a cola de fibrina apresentou maior neovascularização e maior porcentagem de colágeno tipo I e tipo III demonstrando tendências a uma melhor reparação tecidual.

\section{Referências}

1. Fagundes DJ, Taha MO, Monteiro Souza EF. Condutas em cirurgia: adesivos em cirurgia. São Paulo: Editora Atheneu; 2001. p 669-74.

2. Souza M, Fagundes DJ, Gomes PO, Ascenção AM, Guimarães CA, Mendonça Jr ITM, Guimarães AC, Martins VL. Fios de sutura: uma revisão histórica. Rev Ciênc Biol Saúde 2001;2(1):98-100.

3. Fagundes DJ, Taha MO, Rivoire HC. Adesivos cirúrgicos: revisão e atualização. JBM 2002;82(3):101.

4. Bastos da Cunha, E. G. Contribuição ao estudo das reconstituições do trânsito intestinal sem sutura empregando o adesivo 2-butil cianoacrilato [Tese - Livre Docência]. Universidade Federal Fluminense; 1976

5. Shapiro AJ, Dinsmore RC, North JH. Tensile strength of wound closure with cyanoacrylate glue. Am Surg 2001; 67(11):1113-5.

6. Cohn SM, Cross JH, Ivy ME, et al. Fibrine glue terminates massive bleeding after complex hepatic injury. J Trauma 1998; 45: 666-72.

7. Holcomb JB, Pulsateri AE. Dry fibrine dressings reduce blood loss, resuscitation, volume, and improves survival in hypothermic coagulopathic with grade V liver injuries. J Trauma. 1999 ; 47 : 233240 .

8. Jackson MR, MacPhee MJ, Drohan WN, Alving BM. Fibrin sealant: current and potential clinical applications. Blood Coagul Fibrinolysis. 1996; 7(8):737-46.

9. Holcomb JB, Pulsateri AE, Hess JR, et al. Implications of new dry fibrine sealant technology of trauma surgery [ review ]. Surg Clin North Am. 1997; 77 : 943-52.

10. Uranüs $\mathrm{S}$, Mischinger $\mathrm{HJ}$, Pfeifer J, Kronberger L, Rabl H, Werkgartner G, Steindorfer P, Kraft-Kirz J. Hemostatic methods for the management of spleen and liver injuries. World J Surg.1996; 20(8):1107-11.

11. Chen RJ, Fang JF, Lin BC, Hsu YB, Kao JL, Kao YC, Chen MF. Selective application of laparoscopy and fibrin glue in the failure of nonoperative management of blunt hepatic trauma. J Trauma. 1998; 44(4): 691-5.

12. Holcomb JB, McClain JM, Pusateri AE, Beall D, Macaitis JM, Harris RA, MacPhee MJ, Hess JR. Fibrin sealant foam sprayed directly on liver injuries decreases blood loss in resuscitated rats. J Trauma. 2000; 49(2):246-50.

13. Kasai T, Kobayashi K. Searching of the best operative modality for severe hepatic injuries. Surg Gynecol Obstet 1993 ; 177 : 551-55.

14. Edmonson MB. Foreign body reactions to dermabond. Am J Emerg Med. 2001; 19(3):240-1.

15. Jackson MR, MacPhee MJ, Drohan WN, Alving BM. Fibrin sealant: current and potential clinical applications. Blood Coagul Fibrinolysis. 1996; 7(8):737-46.

16. Stagnitti F, Schillaci F, De Pascalis M, Mongardini M, Patrizi V, Cilurso F, Costantini A, Dall'Olio D, Priore F, Tiberi R, Natalini E. L'uso dei collanti in chirurgia d'urgenza. G Chir. , 2001; 22(8-9):309-12.

17. Davidson BR, Burnett S, Javed MS, Seifalian A, Moore D;, Doctor N. Experimental study of a novel fibrin sealant for achieving haemostasis following partial hepatectomy. Br J Surg. 2000; 87(6):790-5.

18. Ochsner MG, Manicalco-Theberge ME, Champion HR. Fibrin Glue as a hemostatic agent in hepatic and spleen trauma. J Trauma. $1990 ; 30: 884-87$. 
Fontes CER, Taha MO, Fagundes DJ, Ferreira MV, Prado Filho OR, Mardegan JM. The repair of liver experimental wound with fibrin glue and cianoacrilate. Acta Cir Bras [serial online] 2004 Jan-Feb;19(1). Available from URL: http:/ /www.scielo.br/acb

ABSTRACT - Purpose: To determinate the role of cianoacrilate and fibrin glue in the repair of the hepatic wound, to evidence the hemostatic capacity of the adhesives and their respective integration to the hepatic tissue. Methods: 30 rats Wistar-EPM1 were separate in 2 groups and submitted to the anesthesia with tiopental in the concentration of $40 \mathrm{mg} / \mathrm{kg}$ EV. Laparotomy was made with exhibition of the liver. A punch of $3 \mathrm{~mm}$ was made in the hepatic right lobe. The animals of group A were treated with the placement of fibrin glue in the wounds, the animals of group B had the wounds treated with cianoacrilate. In the 7th of post-operative period, under anesthesia, the animals suffered the resection of the right hepatic lobe and samples were collected for the histology study procedures (HE and PicroSirius). They were appraised for optical microscopy, the inflammatory response (qualitative criteria of the neutrofiles presence, giants cells, granuloma, neovascularization) and for polarization microscopy, the quantification of collagen (I-young Type and III-matureType). Results: The two adhesives had hemostatic effects in similar times. The wounds treated with fibrin glue showed larger amount of young and mature collagen and a larger amount of neovascularization, while the wounds treated with cianoacrilate showed larger reaction of granuloma. Conclusion: Fibrin glue and cianoacrilate have similar hemostatic effects. The wound treated with fibrin glue present larger neovascularization and larger percentage of collagen type I and type III showing tendency to a better tissue repair without formation of granuloma.

KEY WORDS - Hemostasis. Fibrin tissue adhesive. Liver.

Conflito de interesse: nenhum Fonte de financiamento: CEDITEC

Correspondência:

Carlos Edmundo R. Fontes

Hospital Universitário Regional de Maringá - Depto. Medicina

Av Mandacaru, 1590

87080-000 Maringá-PR

cfontes@teracom.com.br

Data do recebimento: 25/11/2003

Data da revisão: $16 / 12 / 2003$

Data da aprovação: 03/01/2004

Fotos coloridas disponíveis em www.scielo.br/acb 